\title{
The Kensington Gardens and the Solstices
}

\author{
Amelia Carolina Sparavigna
}

Politecnico di Torino

\begin{abstract}
Here we discuss the orientation of two avenues of the Kensington Gardens along the sunrise on solstices.
\end{abstract}

Keywords: Architecture of the Gardens, Satellite Images, SunCalc, Archaeoastronomy.

The Kensington Gardens are one of the Royal Parks of London. The gardens are covering an area of 270 acres, and, with the Hyde Park, Green Park, and St. James's Park form an almost continuous green area in London [1]. The Kensington Gardens are generally regarded as being the western extent of the Hyde Park, however the Gardens have a more formal layout than that of the Park [1].

In origin, the Gardens were the western section of the park created by Henry VIII in 1536 for hunting purposes. At the request of Queen Caroline, in 1728 the Kensington Gardens were separated from the Hyde Park [2]. According to Ref.1, the Gardens were designed by Henry Wise and Charles Bridgeman in order to form a landscape garden, which included the Round Pond and formal avenues [3]. Bridgeman created also the Serpentine between 1726 and 1731 [3]. The part of the Serpentine that lies within Kensington Gardens is known as "The Long Water" [1,3]. A map made by John Rocque in 1754, kindly provided by the British Library [4] (see Figure 1), shows us the plan of the Gardens at the time of Queen Caroline. Previously, the Gardens were designed with formal Dutch patterns [4].

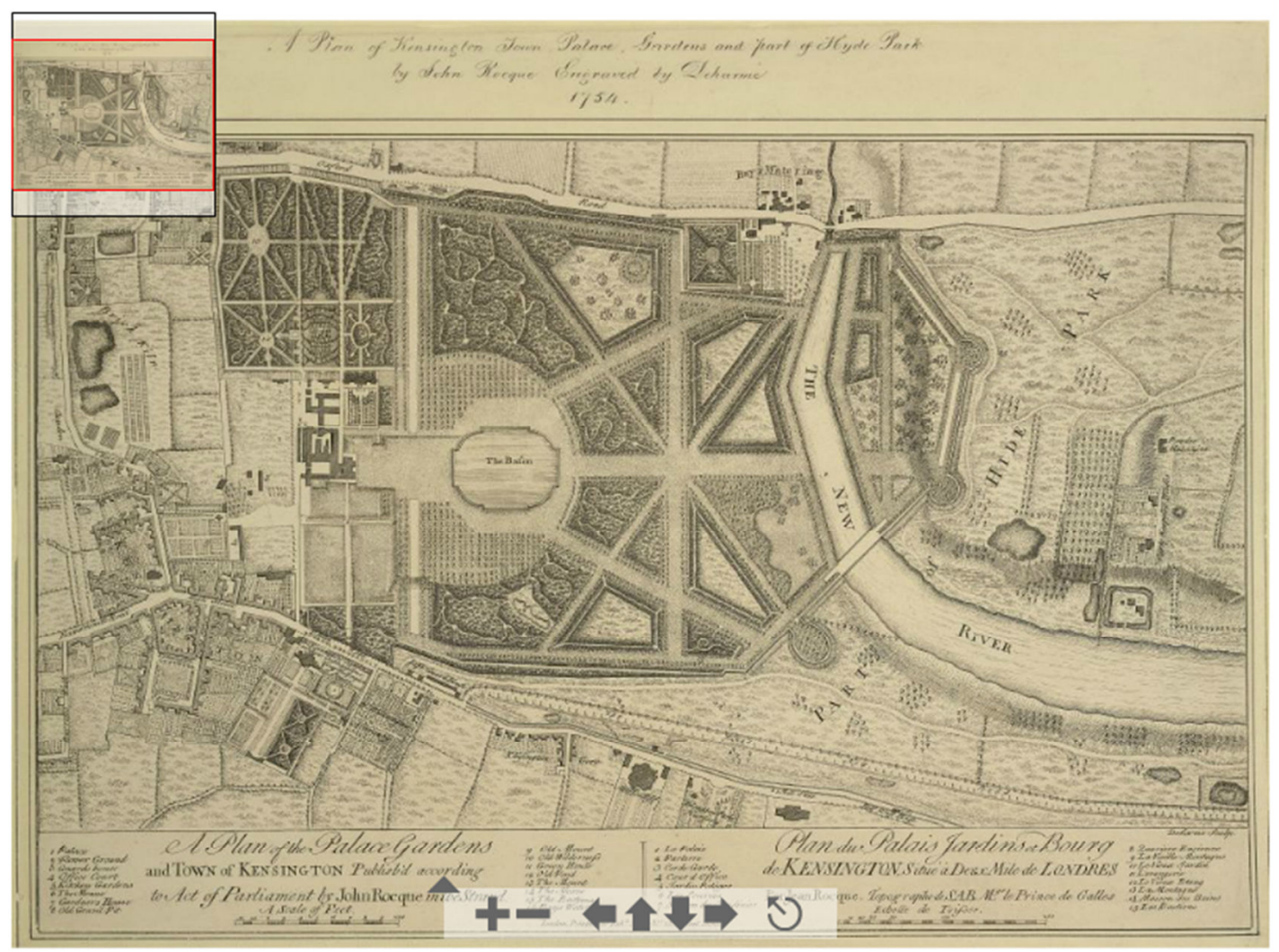

Figure 1: Plan of Kensington Gardens and Kensington Town drawn by John Rocque, 1754 (Courtesy: British Library) 


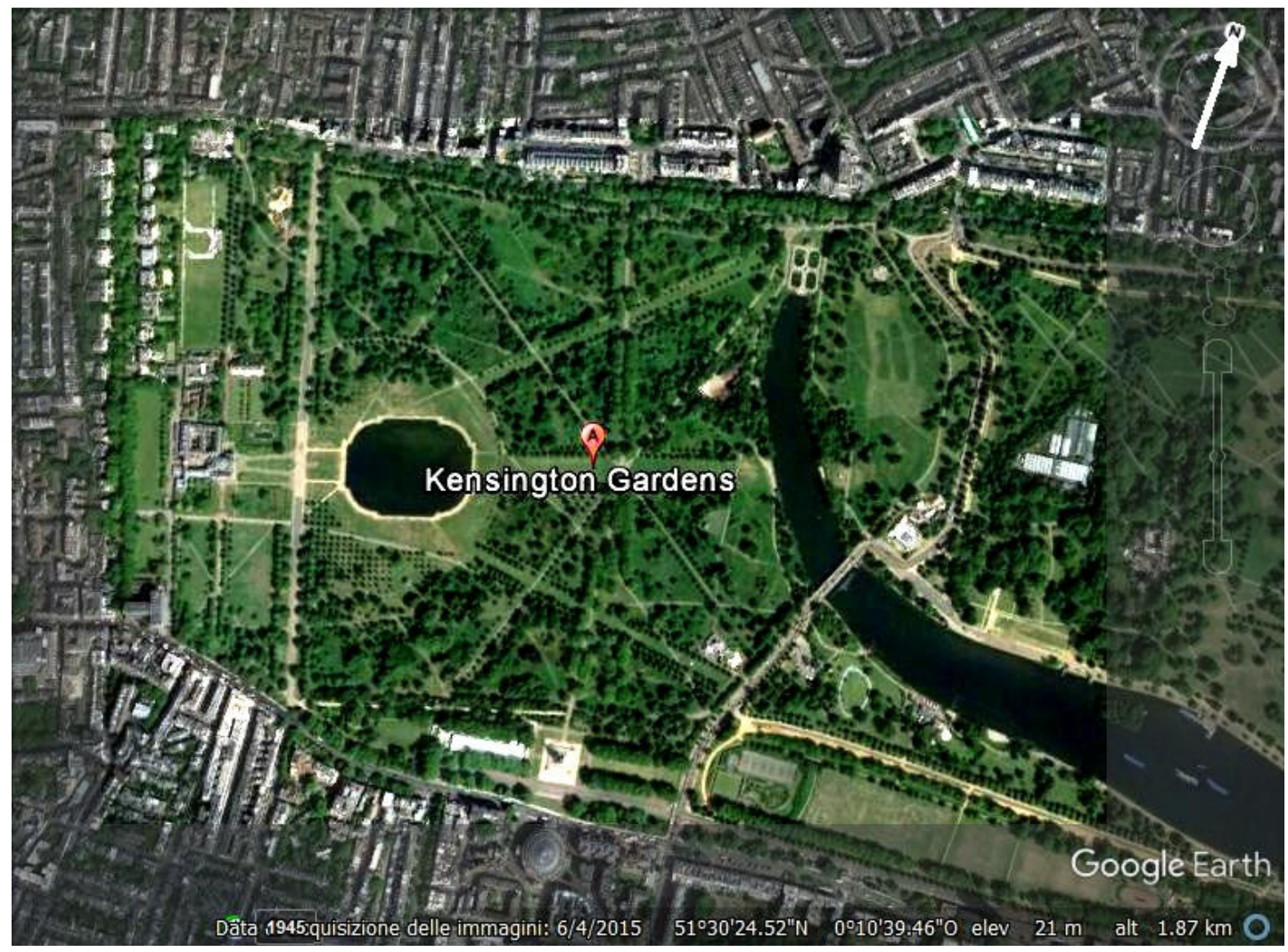

Figure 2: The Kensington Gardens in a Google Earth image (Courtesy: Google Earth). The layout is the same of that shown by Rocque's map.

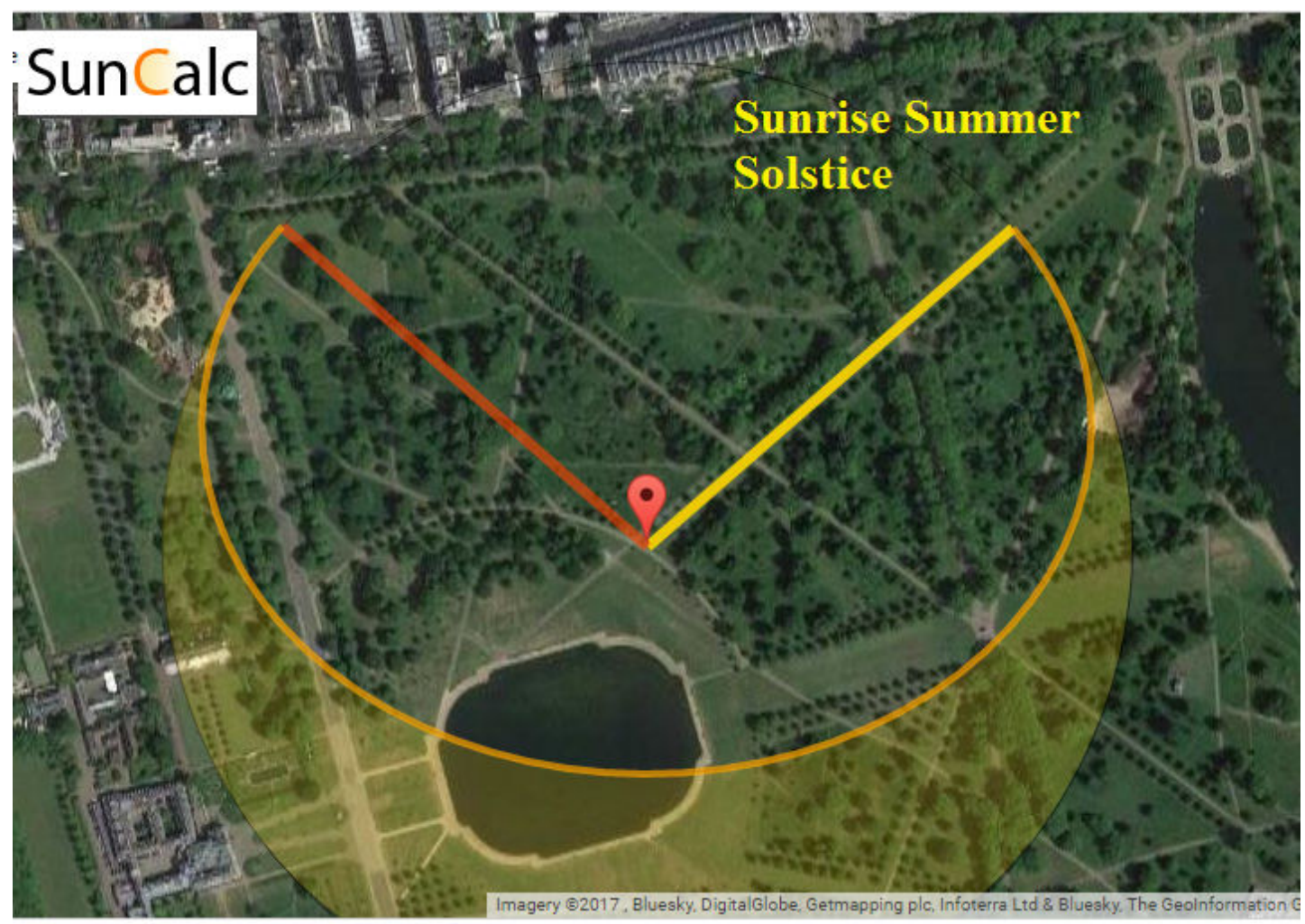

Figure 3: One of the main avenues of the Gardens is aligned along the sunrise on summer solstice, as given by SunCalc.net software. The yellow line represents the direction of sunrise, the red line is giving the direction of the sunset. The orange curve is representing the path of the sun. 
If we use Google Earth (Figure 2), we can observe that the layout of the Gardens that we see today is the same of that depicted in the Rocque's map. To compare the satellite image with the map dated 1754 we rotated it, as given by the white arrow in the Figure 2. It means that the main avenue of the park is not cardinally oriented East-West. However, let us investigate if the Kensington Gardens have other specific orientations and alignments, for instance along the sunrise on summer or winter solstices, alignments that we can find in other gardens [5-11]. As made in the given references, to evidence such astronomical alignments we can use the SunCalc.net software, which is giving sunrise and sunset directions on Google satellite maps for any day of the year. In the case of the Kensington Gardens, we have that one of the main avenues, radiating out from the circle around the pond, is oriented along the sunrise on the summer solstice (Figure 3). Another avenue is oriented along the sunrise on the winter solstice (Figure 4).

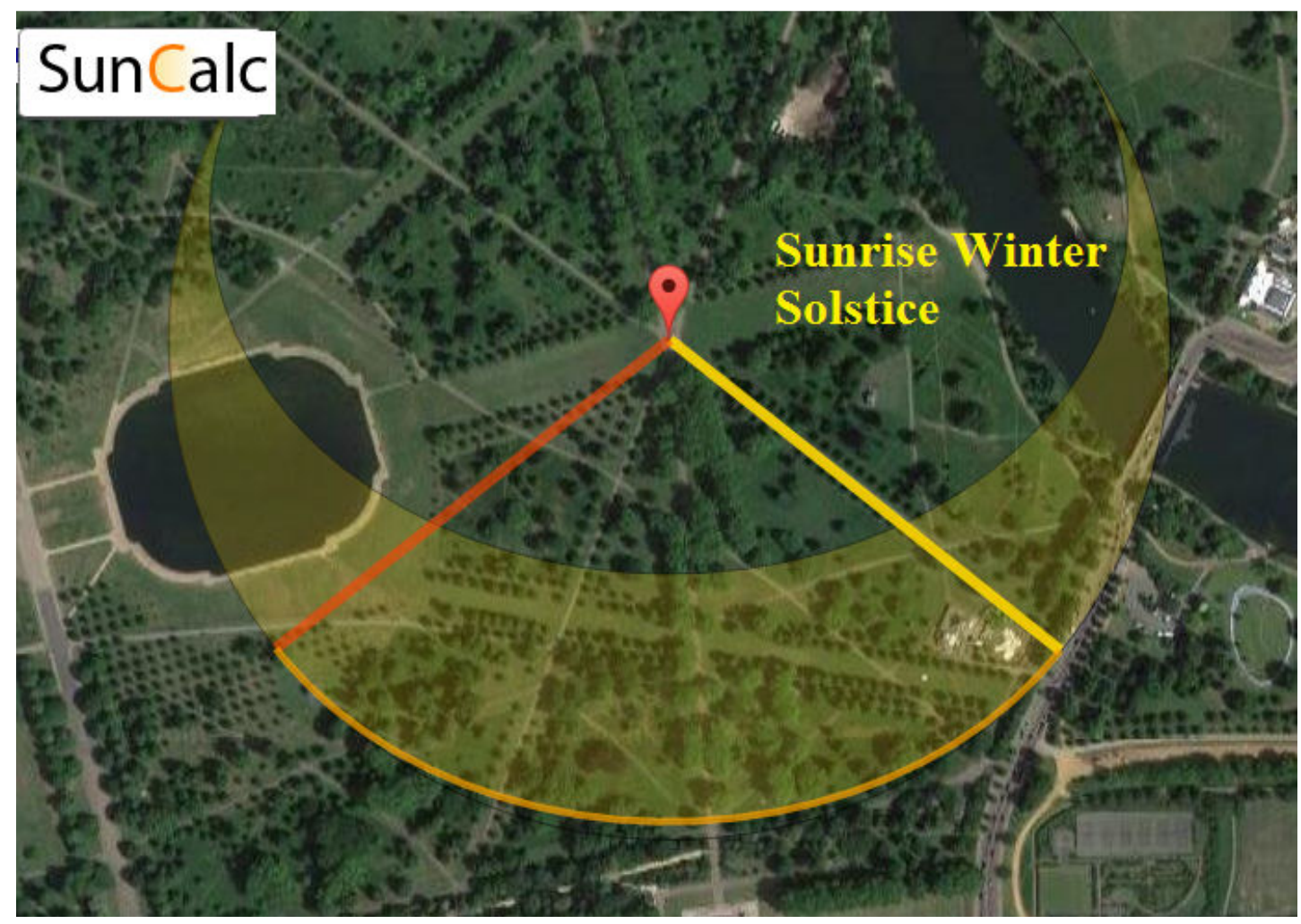

Figure 4: One of the avenues of the Gardens is aligned along the sunrise on winter solstice, as given by SunCalc.net software.

It means that the architects planned the gardens, including two references to the apparent path of the sun, through the sunrise on solstices. As observed in [12], the focus of the garden was the Kensington Palace and "the Round Pond that Bridgeman dug in front of it. Avenues of trees radiated out from the pond like spokes on a wheel" [12]. One of the spokes is the direction of the sunrise on the summer solstice.

In the layout shown by the map of the Figure 1, the astronomical alignments are not evident, because the map is not cardinally oriented but rotated by a few degrees. In fact, the aim of the drawing was probably that of enhancing the symmetry of the planning. However, the use of a software, such as SunCalc or other, can help us in finding any possible alignment along the rising and setting of the sun, in the satellite maps of the observed gardens.

\section{References}

[1] Vv. Aa. (2017). Wikipedia, Kensington Gardens. https://en.wikipedia.org/wiki/Kensington_Gardens

[2] Self, A. (2014). The Birds of London. A\&C Black. ISBN 978-1-408-19404-1.

[3] Skempton, A.W, ed. (2002). A Biographical Dictionary of Civil Engineers in Great Britain and Ireland: 1500-1830. Thomas Telford. p. 341. ISBN 978-0-727-72939-2. 
[4] A plan of the Palace Gardens and town of Kensington. John Rocque, 1754. British Library, http://www.bl.uk/onlinegallery/onlineex/crace/a/007zzz000000010u00002000.html

[5] Sparavigna, A. C. (2013). The Gardens of Taj Mahal and the Sun. International Journal of Sciences, 2 (11), 104-107. DOI: 10.18483/ijSci.346

[6] Sparavigna, A. C. (2015). Observations on the Orientation of Some Mughal Gardens (January 13, 2015). PHILICA, Article number 455. Available at SSRN: https://ssrn.com/abstract=2745160

[7] Sparavigna, A. C. (2013). Solar Azimuths in the Planning of a Nur Jahan's Charbagh, International Journal of Sciences, 2 (12), 8-10. DOI: 10.18483/ijSci.353

[8] Sparavigna, A. C. (2013). The Solar Orientation of the Lion Rock Complex in Sri Lanka, International Journal of Sciences, 2 (11), 60-62. DOI: 10.18483/ijSci.335

[9] Sparavigna, A. C. (2016). Winter Solstice and Lunar Standstills in the Gardens of Villa D'Este (September 27, 2016). SSRN Electronic Journal. DOI: 10.2139/ssrn.2844169

[10] Sparavigna, A. C. (2016). The King's Knot of Stirling Castle and Its Astronomical Orientation (September 10, 2016). SSRN Electronic Journal. DOI: 10.2139/ssrn.2837181

[11] Sparavigna, A. C. (2016). Alignments to Sunrise and Sunset on Solstices in the Layout of Lafayette Square, Washington (May 15, 2016). PHILICA Article, No. 601, 2016. Available at SSRN: https://ssrn.com/abstract $=2783844$

[12] The Royal Parks. Landscape History, Kensington Gardens - The Queen's gardens, https://www.royalparks.org.uk/parks/kensington-gardens/about-kensington-gardens/landscape-history 